УДК 636

https://doi.org/10.32634/0869-8155-2020-340-7-44-48 Тип статьи: Оригинальное исследование Type of article: Original research

Абилов А.И. ${ }^{1}$, Зарипов Ф.Ш. ${ }^{2}$, Дунин М.И. ${ }^{3}$, Пыжова Е.А. ${ }^{4}$

1 ФГБНУ «Федеральный научный центр животноводства - ВИЖ имени академика Л.К. Эрнста» (ФНЦ-ВИЖ им. Л.К. Эрнста) 142132, Россия, Московская область, г. Подольск, п. Дубровицы, д. 60. E-mail: ahmed.abilov@mail.ru ${ }^{2} \mathrm{AO}$ «Головное племенное предприятие «Элита». Республика Татарстан, г. Казань, Высокогорский район, ул. Иске-Казанская 2а. 3 ФГБНУ «Всероссийский научно исследовательский институт племенного дела» (ФГБНУ «ВНИИплем»). 141212, Россия, Московская обл., г. Пушкино, пос. Лесные Поляны, ул. Ленина, д. 13. ${ }^{4}$ ФГБОУ ДПО «Российская академия менеджмента в животноводстве» (ФГБОУ РАMЖ).

E-mail: Elena@ramj.ru

Ключевые слова: эндогенные гормоны, тестостерон, эстрадиол, тироксин, спермопродукция, быки-производители, породы, возраст, происхождение.

Для цитирования: Абилов А.И., Зарипов Ф.Ш., Дунин М.И., Пыжова Е.А. Содержание эндогенных гормонов в сыворотке крови у быков-производителей молочных пород в условиях Республики Татарстан. Аграрная наука. 2020; 340 (7): 44-48.

https://doi.org/10.32634/0869-8155-2020-340-7-44-48 Конфликт интересов отсутствует

Ahmedaga I. Abilov' ${ }^{1}$, Fannur R. Zaripov ${ }^{2}$, Mikhail I. Dunin ${ }^{3}$, Elena A. Pyzhova ${ }^{4}$

${ }^{1}$ L.K. Ernst Federal Science Center for Animal Husbandry. 60, Dubrovitsy, Podolsk, Moscow region, 142132, Russia.

E-mail: ahmed.abilov@mail.ru.

2 Parent breeding enterprise «Elite». 2a, IskeKazanskaya str. Kazan, Republic of Tatarstan

3 Federal State Budgetary Scientific Institution "All-Russian Scientific Research Institute of Breeding". 13, Lenin st., Lesnie Polyani, Pushkino, Moscow region, 141212, Russia.

${ }^{4}$ Federal State Budgetary Educational Institution of Additional Professional Education. "Russian Academy of Management in Animal Breeding" E-mail: Elena@ramj.ru

Key words: endogenous hormones, testosterone, estradiol, thyroxin, sperm production, bulls-producers, breeds, age, origin.

For citation: Abilov A.I., Zaripov F.R., Dunin M.I., Pyzhova E.A. Content of endogenous hormones in the blood serum of milking breeds bulls-producers in the conditions of Tatarstan region. Agrarian Science. 2020; 340 (7): 44-48. (In Russ.)

https://doi.org/10.32634/0869-8155-2020-340-7-44-48 There is no conflict of interests

Содержание эндогенных гормонов в сыворотке крови у быков-производителей молочных пород в условиях Республики Татарстан

\begin{abstract}
PEЗЮME
Актуальность и методика. Исследования проведены на 35 быкахпроизводителях молочных пород (голштинская черно-пестрой масти, холмогорская татарстанского типа с прилитием голштинской крови и чернопестрая) в возрасте 1,8-8 лет в осенний сезон года в условиях Республики Татарстан (Поволжье). Работа посвящена изучению концентрации эндогенных гормонов (тестостерона, эстрадиола, тироксина) и их предшественника холестерина в сыворотке крови в день взятия семени и их взаимосвязь с репродуктивной функцией.
\end{abstract}

Результаты. Установлено, что в зависимости от породы имеются различия по концентрации эндогенных гормонов в сыворотке крови. Общее число сперматозоидов в эякуляте имеет положительную связь с содержанием тестостерона в сыворотке крови в день взятия семени: чем выше уровень тестостерона, тем больше общее число сперматозоидов в эякуляте $(P<0,001)$. Самый низкий уровень эндогенных гормонов и холестерина зарегистрирован у быков-производителей голштинской породы голландской селекции. Возраст существенно влияет на содержание эндогенных гормонов: на концентрацию тестостерона в сыворотки крови, эстрадиола и тироксина $(P<0,05)$. Не выявлена связь возраста с содержанием холестерина. Предлагается при андрологической диспансеризации у быков-производителей проводить мониторинг содержания эндогенных гормонов в сыворотке крови как дополнительный тест для диагностики репродуктивной функции животных.

\title{
Content of endogenous hormones in the blood serum of milking breeds bulls-producers in the conditions of Tatarstan region
}

\begin{abstract}
Relevance and methods. 35 bulls-producers of milking breeds (holstein of black-and-white paint, holmogorskaya of Tatar type with flow of holstein blood, black-and-white) were inspected in the age 1,8-8 years old in the autumn season in conditions of Tatarstan Republic (Volga region, Povolzhye). The subject of the work is to research the concentration of endogenous hormones (testosterone, estradiol, thyroxin) and their precursor - cholesterol in the blood serum in the day of semen collection and their intercommunication reproductive function.

Results. Was established that, depending of the breed there are differences in concentration of endogenous hormones in the blood serum. Total number of spermatozoids in ejaculate has positive relation with testosterone content in the blood serum in the day of collection semen: the higher level of testosterone, the higher concentration of spermatozoids in ejaculate $(P<0.001)$. The lowest level of endogenous hormones and cholesterin is registered in holstein breed of Holland selection. The age wields major influence on content of endogenous hormones: on concentration of testosterone in the blood serum, of estradiol and thyroxin $(P<0.05)$. Unascertained is interaction of the age and the containing of cholesterin. Suggested during andrological health examination of bulls-producers to monitor the content of endogenous hormones in the blood serum as extra test for diagnostic of reproduction function of animals.
\end{abstract}

Поступила: 17 юиня

После доработки: 30 июля

Принята к публикации: 31 июля
Received: 17 june

Revised: 30 july

Accepted: 31 july 


\section{Введение}

Половые гормоны стероидного строения (андрогены) играют важную роль в жизнедеятельности организма. Они обеспечивают половую дифференциацию, определяют функцию яичников, простаты, семенников [8].

Сперматогенез и синтез гормонов семенниками находятся под контролем гонадотропинов и тестостерона. Они легко проникают в цитоплазму, где каждый контролирует функцию клетки при участии специфических высокомолекулярных белковых рецепторов, реагирующих на тестостерон [2]. Андрогены представляют собой группу стероидных гормонов, их биосинтез осуществляется в основном в интерстициальных клетках Лейдига семенников. В митохондриях клеток Лейдига холестерин превращается в прегненолон, который под действием ферментов переходит в тестостерон. Секреция тестостерона контролируется лютенизирующим гормоном и имеет импульсный характер: выбросы тестостерона из клеток Лейдига происходят каждые 6090 минут. Например, за сутки у человека секретируется около 7 мг тестостерона, который инактивируется в печени и выводится в основном с мочой [11].

Большая часть андрогенов (97-98\%) находится в связанном с белками плазмы состоянии, и только 2-3\% циркулируют свободно и считаются биологически активными. В процессе образования комплекса гормонов основную роль выполняет тестостерон-эстрадиол, связывающий глобулин, обладающий высоким сродством к тестостерону и эстрадиолу. Этот белок выполняет транспортную, регулирующую и защитную функцию. Некоторое количество андрогенов взаимодействует с сывороточным альбумином [10].

Имеются данные, что концентрация тестостерона в сыворотке крови быков-производителей голштинской породы показывает зависимость от возраста и сезона года. Оптимальная концентрация тестостерона была зафиксирована в летне-осенний период в Московском регионе у производителей в трех-четырехлетнем возрасте [3]

Низкий уровень тестостерона в сыворотке крови и повышение уровня ЛГ и ФСГ могут быть причиной первичной и вторичной тестикулярной недостаточности (гипогонадизма). Низкий уровень тестостерона - это дефицит глобулинсвязывающего полового гормона, что может быть следствием концентратного типа кормления: ожирение [11].

Ожирение является одним из ключевых факторов, приводящим к нарушению баланса стероидных половых гормонов и повышению уровня эстрогенов $[21,23,16]$.

Например, при повышении уровня эстрадиола выше нормы отмечено снижение качественных и количественных характеристик эякулята $[4,15]$.

Некоторые авторы считают, что гиперандрогенизация сопровождается снижением уровня тестостерон-эстрадиол-связывающего глобулина в сыворотке крови и, наоборот, гиперэстрогенизация и гипертиреоз ведут к повышению тестостерон-эстрадиол-связывающего глобулина и снижению функции свободного тестостерона [22].

Физиологическая роль андрогенов проявляется на вcex этапах функционирования мужского организма [9]. Показано, что для поддержания половой активности требуется в 2 раза меньший уровень тестостерона в крови, чем для нормального функционирования механизма обратной связи между семенниками и гипоталамо-гипофизарной системой [10].
Установлена также роль тестостерона в увеличении синтеза ДНК и активации клеточного деления, активации биогенеза, рибо-полисом и синтеза белков, в том числе андрогензависимых ферментов, а также в структурных изменениях соответствующих участков хроматина и усилении активности ДНК и синтеза различных видов РНК [10].

По мнению некоторых авторов, тестостерон необходим для индукции сперматогенеза в пубертатном периоде и его поддержания в зрелом возрасте. Показана его стимулирующая роль в размножении сперматогониев и мейоз сперматоцитов. Установлено, что даже незначительное нарушение ритма секреции тестостерона или малейший его дефицит могут привести к торможению сперматогенеза [11].

У всех млекопитающих сперматогенез находится под контролем пептидных и стероидных гормонов: ФСГ, ЛГ, тестостерон, эстрадиол и другие. [20].

Несмотря на то, что эстрадиол считается половым гормоном самок, он также вырабатывается еще и семенниками, и надпочечниками самца и имеет специфическое влияние на половые органы и на развитие вторичных половых признаков, а в обмене веществ - на биосинтез липидов [5]. Под их влиянием происходит стимуляция ретикуло-эндотелиальной системы и повышение резистентности организма к инфекциям, а также усиление регенерации тканей при повреждении [2].

Эстрадиол совместно с лютенизирующим гормоном (ЛГ) необходим для собственного сперматогенеза, а именно ЛГ вызывает секрецию андрогенов в семенниках, стимулирует развитие интерстициальной ткани и выработку мужского гормона тестостерона [8], вызывая разрастания семенных канальцев - стимулирует начальные стадии сперматогенеза [7].

Основные функции эстрогенов у мужских особей обеспечение механизма обратной отрицательной связи через гонадотропины (ЛГ и ФСГ), регулировка синтеза тестостерона в яичках $[13,6]$.

В молодом мужском организме выявлена четкая корреляция между уровнем тестостерона и эстрадиола, а также уровнем их свободных фракций. Наибольшая часть эстрадиола в плазме крови связана с глобулином, связывающим половые стероиды (ГСПС), и альбуминами, и только 1-2 \% присутствует в свободной форме биологически активной фракции, способной проникать в клетки [18].

Отмечена взаимосвязь между содержанием эстрадиола и характеристиками семени и воспроизводительными способностями самцов - чем ниже концентрация эстрадиола в сыворотке крови быков-производителей голштинской породы в день взятия семени, тем выше результативность осеменения коров от полученного семени [1]

Высокая положительная корреляция выявлена также между концентрацией семени и содержанием тестостерона и отрицательная - между $\mathrm{pH}$ семени и тестостероном [14] в сыворотке крови у быков симментальской породы в зависимости от сезона года [17].

Изучая уровень сывороточного тестостерона в дородовом и послеродовом периодах развития быков, специалисты выявили, что уровень тестостерона зависит от возраста в период от 2-4 месячного до 2-х летнего возраста (при статистически достоверных различиях), а у быков старше такая взаимосвязь уже не была достоверной, хотя отмечена тенденция увеличения [19].

Некоторые авторы утверждают, что имеется определенная взаимосвязь между содержанием эндогенных 
гормонов и наличием спермальных аутоантител в сыворотке крови быков-производителей [1].

Считается, что получение и анализ новых данных по уровню содержания всех половых стероидов в крови (андрогенов, гестагенов, эстрогенов) может позволить лучше понять физиологическую и патофизиологическую функцию не только женских гормонов в организме самок, но и так называемых женских половых гормонов в мужском организме [12].

Таким образом, вышеизложенный краткий обзор показывает значительную роль эндогенных гормонов тестостерона и эстрадиола - и их значение для нормального развития и общего метаболизма в организме млекопитающих. Это позволяет считать, что назрела необходимость уточнить концентрацию эндогенных гормонов у быков-производителей различных молочных пород в одинаковых условиях содержания, кормления и эксплуатации в организме животных новой генетической формации и на основе научно обоснованных данных принять меры к улучшению отрасли в целом. Это, во-первых, создаст новые перспективы в селекции, и, во-вторых, появится возможность приобретения более глубоких знаний биологических процессов, происходящих в организме животных.

Цель исследований - изучить состояние эндогенных гормонов у быков-производителей молочных пород в условиях Республики Татарстан в зависимости от возраста, породы, селекции и их взаимосвязь со спермопродукцией.

Научная новизна. Впервые в условиях Республики Татарстан изучены эндогенные гормоны: тестостерон, эстрадиол, тироксин и их предшественник холестерин у быков-производителей разных пород в сравнительном аспекте, а также в зависимости от возраста, породы, селекции, происхождения животных - и их взаимосвязь с репродуктивной функцией самцов.

\section{Материалы и методы исследований}

Работа выполнена на базе ГПП «Элита» Республики Татарстан в 2018 году и ФГБНУ ФНЦ ВИЖ им. Л.К. Эрнста.

В опыте использованы 35 голов высокоценных быков-производителей разной селекции и пород в возрасте 1,5-8 лет (АО ГПП «Элита», Республика Татарстан).

Кровь для анализа взяли осенью в период календарных мероприятий по диспансеризации животных в течение 20-30 минут после взятия семени.

Концентрацию эндогенных гормонов в сыворотке крови быков-производителей определяли методом
ИФА-реагентов отечественного производства: для тестостерона - «Иммуна-ФА-ТС», для эстрадиола «Иммуна-ФА-эстрадиол», для тироскина - «Иммуна-ФА-тироксин» (ЗАО «Иммунотех», Москва) на приборе Униплан (АИФР 01), ЗАО «Пикон», Москва).

Содержание холестерина в сыворотке крови определяли на автоматическом анализаторе «Chem Well-2902» (Awareness Technolgy, США).

Показатели семени изучали традиционно по объему, концентрации и по общему числу сперматозоидов в эякуляте, согласно используемым технологиям, принятым на племпредприятии, а также с помощью спермоанализатора Биола SFA-500 отечественного производства.

Гормоны изучали у быков-производителей в зависимости от породы (голштинская черно-пестрой масти, холмогорская и черно-пестрая), страны происхождения (Россия, США, Нидерланды) в разных возрастных категориях (2-8 лет). Полученные данные статистически обработаны с помощью MS Excel с применением критерия $\mathrm{t}$-Стьюдента.

\section{Результаты исследований}

Анализ по содержанию эндогенных гормонов и их предшественника - холестерина и их взаимосвязь со спермопродукцией (общее число сперматозоидов в эякуляте) в зависимости от породы показаны в таблице 1.

Анализ таблицы 1 показывает различие содержания тестостерона в зависимости от породы. Сравнительно низкий уровень тестостерона (28,21 ммоль/л) отмечен у быков-производителей черно-пестрой породы, однако за счет малочисленности черно-пестрой породы (всего 2 головы) вывод сделать невозможно. У холмогорской породы (ТT) отмечен высшие показатели тестостерона и соотношения тестостерона к эстрадиолу.

Концентрация эстрадиола варьировала 0,31-

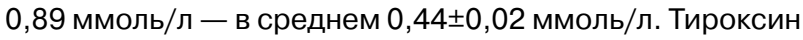
находился на уровне 96,54 ммоль/л с вариабельностью от 27,23 до 149,03 ммоль/л.

По содержанию холестерина существенной разницы между голштинской и холмогорской породой не отмечено. По этому показателю данные регистрировали между 3,54-3,69 при нормативном диапазоне. Однако установлено существенное отличие животных черно-пестрой породы по общему числу сперматозоидов в эякуляте по сравнению с голштинской у холмогорской $(P<0,001)$. Полученные данные соответствуют результатам других авторов [14], которые показали: чем ниже уровень тестостерона в крови, тем ниже репродуктивные способности самцов-производителей.

Таблица 1. Содержание эндогенных гормонов и холестерина в сыворотке крови быков-производителей различных пород и их влияние на репродуктивную функцию

Table 1. The content of endogenous hormones and cholesterol in the blood serum of breeding bulls of various breeds and their effect on reproductive function

\begin{tabular}{|c|c|c|c|c|c|c|}
\hline \multirow[t]{2}{*}{ Породы } & $\begin{array}{c}\text { Тестостерон, } \\
\text { ммоль/л }\end{array}$ & $\begin{array}{c}\text { Эстрадиол, } \\
\text { ммоль/л }\end{array}$ & $\begin{array}{l}\text { Тироксин, } \\
\text { ммоль/л }\end{array}$ & $\begin{array}{c}\text { Соотношение } \\
\text { Тестостерон : } \\
\text { Эстрадиол }\end{array}$ & $\begin{array}{c}\text { Холестерин, } \\
\text { ммоль/л }\end{array}$ & $\begin{array}{c}\text { Общее число } \\
\text { спер-ов в эяку- } \\
\text { ляте, млрд }\end{array}$ \\
\hline & $\mathrm{M} \pm \mathrm{m}$ & $M \pm m$ & $M \pm m$ & $M \pm m$ & $M \pm m$ & \\
\hline Голштинская & $32,16 \pm 4,00$ & $0,46 \pm 0,03$ & $98,30 \pm 3,76$ & $74,24 \pm 10,38$ & $3,69 \pm 0,09$ & $9,94 \pm 0,11$ \\
\hline Холмогорская (ТТ) & $40,28 \pm 5,54$ & $0,41 \pm 0,02$ & $92,26 \pm 2,15$ & $95,13 \pm 11,72$ & $3,54 \pm 0,01$ & $10,00 \pm 0,48$ \\
\hline Черно-пестрая & $28,21 \pm 24,29$ & $0,37 \pm 0,03$ & $97,73 \pm 2,20$ & $71,06 \pm 59,47$ & - & $7,19 \pm 0,32^{\star \star \star}$ \\
\hline ВСЕГО: & $34,26 \pm 3,25$ & $0,44 \pm 0,02$ & $96,54 \pm 2,57$ & $80,03 \pm 8,05$ & - & $9,73 \pm 0,11$ \\
\hline
\end{tabular}


Таблица 2. Концентрация эндогенных гормонов и холестерина в сыворотке крови быков-производителей голштинской породы в зависимости от происхождения

Table 2. Concentration of endogenous hormones and cholesterol in the blood serum of bulls-producers of the Holstein breed, depending on the origin

\begin{tabular}{|c|c|c|c|c|c|c|}
\hline \multirow[t]{2}{*}{ Страна } & \multirow{2}{*}{$\begin{array}{c}\text { Количество быков } \\
\text { (n) }\end{array}$} & $\begin{array}{l}\text { Тестостерон, } \\
\text { ммоль/л }\end{array}$ & Эстрадиол, ммоль/л & $\begin{array}{l}\text { Тироксин, } \\
\text { ммоль/л }\end{array}$ & $\begin{array}{c}\text { Соотношение } \\
\text { Тестостерон: Эстрадиол }\end{array}$ & $\begin{array}{c}\text { Холестерин, } \\
\text { моль/л, }\end{array}$ \\
\hline & & $M \pm m$ & $M \pm m$ & $M \pm m$ & $M \pm m$ & $M \pm m$ \\
\hline Голландия & 4 & $20,87 \pm 65,52$ & $0,37 \pm 0,02$ & $87,60 \pm 4,48$ & $55,48 \pm 16,30$ & $3,56 \pm 0,12$ \\
\hline США & 9 & $36,36 \pm 7,11$ & $0,45 \pm 0,03$ & $95,36 \pm 3,61$ & $84,47 \pm 18,78$ & $3,57 \pm 0,16$ \\
\hline РФ & 10 & $32,91 \pm 6,02$ & $0,50 \pm 0,06$ & $105,22 \pm 7,42$ & $72,53 \pm 16,16$ & $3,85 \pm 0,12$ \\
\hline ВСЕГО: & 23 & $32,16 \pm 4,00$ & $0,46 \pm 0,03$ & $98,30 \pm 3,76$ & $74,24 \pm 10,38$ & $3,69 \pm 0,09$ \\
\hline
\end{tabular}

Учитывая, что четкие нормативные показатели содержания эндогенных гормонов у быков-производителей отсутствует, мы сделали вывод на основе собственных исследований предыдущих лет на базе других племпредприятий [1], а именно, изученные показатели по содержанию гормонов у быков-производителей ГПП «Элита» сходны с показателями других племпредприятий, то есть гормональный статус сильно не нарушен.

Учитывая, что на данном племпредприятии содержатся в основном быки-производители голштинской породы, мы провели исследование по содержанию эндогенных гормонов и холестерина в сыворотке крови производителей в зависимости от селекции и страны происхождения животных (табл. 2).

Анализ данных содержания эндогенных гормонов в сыворотке крови у 23-х быков-производителей голштинских пород в зависимости от их происхождения показал, что самый высокий уровень тестостерона отмечен в крови быков-производителей американской селекции и составляет 36,36 ммоль/л. Сравнительно низкий - у производителей голландской селекции (20,87 ммоль/л), что на 75\% ниже уровня животных американской и на 53\% российской селекций.

По содержанию эстрадиола в крови у быков-производителей голландской селекции сравнительно низкий показатель - 0,37 ммоль/л. Самый высокий показатель отмечен у животных российской селекции - 0,53 ммоль/л, что выше показателей голландской и американской селекций на $35 \%$ и на 11\%, соответственно.

Таким образом, выявлено, что быки-производители голландской селекции по содержанию эндогенных гормонов и их предшественника холестерина имеют сравнительно низкий уровень по сравнению с животными американского и российского происхождения в условиях Республики Татарстан.
На следующем этапе исследований проведен анализ по содержанию изучаемых гормонов в зависимости от возраста быков-производителей (табл. 3).

Анализ данных по содержанию эндогенных гормонов в сыворотки крови в зависимости от возраста у быков-производителей показал, что тестостерон и возраст взаимосвязаны: чем старше быки-производители, тем больше содержание тестостерона в крови. Например, до 4-летнего возраста тестостерона у семи быков-производителей отмечен на уровне 23,84 ммоль/л, а в возрасте от 4 до 6 лет концентрация гормона увеличивается на 43\% и составляет 34,17 ммоль/л. В возрасте больше 6-ти лет показатель почти удваивается, по сравнению с возрастом до 4-лет, и составляет 44,95 ммоль/л $(P<0,05)$.

Содержание эстрадиола в сыворотке крови у быков-производителей в возрасте от 4 до 6 лет самый высокий показатель - 0,46 ммоль/л $(P<0,01)$, что на $17,35 \%$ больше, по сравнению с быками-производителями в возрасте до 4-х лет (0,39 ммоль/л) и на 7\% больше в более зрелом возрасте (свыше 6-ти лет 0,43 ммоль/л)

Аналогичная картина была зарегистрирована и по содержанию тироксина в сыворотке крови. В возрасте 4-6 лет его содержание было выше, чем у молодых быков $(P<0,05)$. Уровень холестерина находился в пределах нормативного диапазона - 3,52-3,83 ммоль/л.

\section{Заключение}

Таким образом, установлено, что между породами быков-производителей имеются достоверные различия по уровню содержания тестостерона и эстрадиола.

Общее число сперматозоидов в эякуляте зависит не только от породы, но и от уровня тестостерона в сыворотке крови в день взятия семени. Между черно-пестрой породой и животными голштинской и холмогорской татарстанского типа имеются различия $(P<0,01)$.

Таблица 3. Содержание эндогенных гормонов в сыворотке крови быков-производителей в зависимости от возраста

Table 3. The content of endogenous hormones in the blood serum of breeding bulls depending on age

\begin{tabular}{|c|c|c|c|c|c|c|}
\hline \multirow[t]{2}{*}{ Возраст (мес.) } & \multirow{2}{*}{$\begin{array}{c}\text { Количество быков } \\
\text { (n) }\end{array}$} & $\begin{array}{l}\text { Тестостерон, } \\
\text { ммоль/л }\end{array}$ & Эстрадиол, ммоль/л & $\begin{array}{c}\text { Тироксин, } \\
\text { ммоль/л }\end{array}$ & $\begin{array}{c}\text { Соотношение } \\
\text { Тестостерон: Эстрадиол }\end{array}$ & $\begin{array}{c}\text { Холестерин, } \\
\text { моль/л, }\end{array}$ \\
\hline & & $M \pm m$ & $M \pm m$ & $M \pm m$ & $M \pm m$ & $M \pm m$ \\
\hline $20-48$ & 7 & $23,84 \pm 6,00$ & $0,39 \pm 0,02$ & $88,31 \pm 2,60$ & $60,80 \pm 15,30$ & $3,83 \pm 0,16$ \\
\hline $49-72$ & 21 & $34,17 \pm 4,42$ & $0,46 \pm 0,03^{\star}$ & $100,39 \pm 3,90^{\star *}$ & $78,08 \pm 11,37$ & $3,59 \pm 0,09$ \\
\hline 72 и выше & 7 & $44,95 \pm 5,46^{\star \star}$ & $0,43 \pm 0,02$ & $93,22 \pm 2,66$ & $105,10 \pm 11,82$ & $3,52 \pm 0,09$ \\
\hline
\end{tabular}


Сравнительно низкие значения изучаемых показателей отмечены у представителей голштинской породь голландской селекции.

Различия по уровню эндогенных гормонов в сыворотке крови быков-производителей на статистически достоверном уровне зарегистрированы: между возрастными группами 20-48 и 72 и выше месяцев $(P<0,05)$ по содержанию тестостерона; по эстрадиолу между 20-48 и 49-72 месяцев; по тироксину - выше значения

\section{ЛИТЕРАТУРА}

1. Абилов, А.И., Амерханов Х.А., Ескин Г.В., Федорова Е.В., Жаворонкова Н.В., Комбарова Н.А., Варенников М.В. Эндогенные гормоны у быков-производителей в новой генерации и их связь с титром аутоиммунности. Зоотехния. 2013;(9):25-28.

2. Алиев, А.А. Обмен веществ у жвачных животных. М.: НИЦ «Инженер». 1997. 419 с.

3. Амерханов Х.А., Абилов А.И., Ескин Г.В., Комбарова Н.А., Турбина И.С., Федорова Е.В., Вареников М.В., Гусев И.В. Содержание тестостерона и холестерина в сыворотке крови у быков - производителей в зависимости от сезона года. Сельскохозяйственная биология. 2014;(2):59-66.

4. Гуторова, Н.В., Осадчук Л.В., Клещев М.А. и др. Качество спермы и уровни репродуктивных гормонов у мужчин Кемеровской популяции. Проблемы репродукции. 2010;(6):86-90.

5. Зверева. Г.В., Хомин С.П. Гинекологические болезни коров. Монография. Киев: Урожай. 1976. 148 с.

6. Калинченко С.Ю., Тюзиков И.А. Практическая андрология. М.: Практическая медицина. 2009. 400 с.

7. Козло Н.Е., Легошин Г.П. Организация и техника воспроизводства сельскохозяйственных животных. Монография. М.: Колос. 1979. 176 с.

8. Милованов В.К. Биология воспроизведения и искусственное осеменение с.-х. животных. М.: Изд-во с.-х. лит-ры, журналов и плакатов. 1962. $696 \mathrm{c}$.

9. Резников А.Г. Половые гормоны и дифференциация мозга. Киев: Наукова думка. 1982. 252 с.

10. Резников А.Г., Варга С.В. Антиандрогены. М.: Медицина. 1988. 208 с

11. Свердлофф Р., Бхасин Ш. Нарушение половой функции у мужчин. Эндокринология. Практика: под. ред. Н.М. Лавина. М., 1999. С. 369-392.

12. Тюзиков И.А., Калинченко С.Ю., Ворслов Л.О., Тишова Ю.А. Роль эстрогенов в мужском организме. Андрология и генитальная хирургия. 2014;(4):8-12.

13. Шилл, В.Б., Комхаир Ф., Харгрив Т. Клиническая андрология. М.: ГЭОТАР-Медиа. 2011.800 с

14. Chacur, M.G.M., Mizusaki K.T., L.R.A. Filho Gabriel, Oba E., Ramos A.A Seasonal effects on semen and testosterone in Zebu and Taurine bulls. Acta Scientiae Veterinariae. 2013;(41):1110.

15. Fejes I., Koloszar S., Zavaczkiz Z.. et al. Effect of body weight on testosterone, estradiol ratio in oligozoospermie patients. Andrologi archive. 2006. P.52, 97-102.

16. Gates M.A. R.A.Mekary, G.R. Chiu et al. Sex steroid hormone levels and body composition in men. J Clin Endocrinol Metab. 2013;98(6):2442-2450.

17. Javed M.T., Abrar K., Mumtaz A. Influence of season on seminal plasma testosterone and oestrogen in healthy and abnormal bulls and their relationship with other semen parameters. Veterinary Archive. 2000;70(3):141-149.

18. Jockenhovel F. Male hypogonadism. Auflage-Bremen: UNI-MED. 2004. $188 \mathrm{p}$.

19. Kozumplik J. The level of plasma testosterone during the prenatal and postnatal period of development in bulls. Acta Vet. Brno. 1981;(50):27-32.

20. Kumanov P., Nandipati K., Tomova A., Agarwal A. Inhibin B is a better marker of spermatogenesis than other hormones in the evaluation of male factor infertility. Fertil. Steril. 2006;86(2):32-338

21. Schneider G., Kirschner M.A., Berkowitz R. and Ertel N.H. Increased estrogen production in obese men. The Journal of Clinical Endocrinology \& Metabolism. 1979;48(4):633-638.

22. Wagner R.K. Acta endocrinology. 1978. P.73.

23. Zumoff B., G.W. Strain, J. Kream et al. Obese young men have elevated plasma estrogen levels but obese premenopausal women do not. Metabolism. 1981;30(10):1011-1014.

\section{ОБ АВТОРАX:}

Абилов Ахмедага Имаш оглы, доктор биол. наук, профессор, главный научный сотрудник

Зарипов Фаннур Рафхатович, генеральный директор

Дунин Михаил Иванович, кандидат биологических наук Пыжова Елена Анатольевна, кандидат биологических наук доцент в группе 49-72 месяцев в сравнении с молодыми животными (20-48 мес.) при $P<0,05$.

\section{Выводы}

Мониторинг содержания уровня эндогенных гормонов в крови быков-производителей в день взятия семени может быть использован как дополнительный тест при андрологической диспансеризации для диагностики репродуктивной функции животных.

\section{REFERENCES}

1. Abilov, A.I., Amerkhanov Kh.A., Eskin G.V., Fedorova E.V., Zhavoronkova N.V., Kombarova N.A., Varennikov M.V. Endogenous hormones in sire bulls in a new generation and their relationship with the titer of autoimmunity. Animal science. 2013;(9):25-28. (In Russ.)

2. Aliev, A.A. Metabolism in ruminants. M.: Research Center "Engineer". 1997. 419 p. (In Russ.)

3. Amerkhanov Kh.A., Abilov A.I., Eskin G.V., Kombarova N.A., Turbina I.S., Fedorova E.V., Varenikov M.V., Gusev I.V. The content of testosterone and cholesterol in the blood serum of bulls - producers, depending on the season of the year. Agricultural biology. 2014;(2):59-66. (In Russ.)

4. Gutorova, N.V., Osadchuk L.V., Kleschev M.A. and others. Sperm quality and levels of reproductive hormones in men of the Kemerovo population. Reproduction problems. 2010;(6):86-90. (In Russ.)

5. Zvereva. G.V., Khomin S.P. Gynecological diseases of cows. Monograph. Kiev: Harvest. 1976. 148 p. (In Russ.)

6. Kalinchenko S.Yu., Tyuzikov I.A. Practical andrology. M. Practical Medicine. 2009. 400 p. (In Russ.)

7. Kozlo N.E., Legoshin G.P. Organization and technique of reproduction of farm animals. Monograph. M.: Kolos. 1979. 176 p. (In Russ.)

8. Milovanov V.K. Reproduction biology and artificial insemination agricultural animals. M. 1962. 696 p. (In Russ.)

9. Reznikov A.G. Sex hormones and brain differentiation. Kiev: Naukova Dumka. 1982. 252 p. (In Russ.)

10. Reznikov A.G., Varga S.V. Antiandrogens. M.: Medicine. 1988. 208 p. (In Russ.)

11. Sverdloff R., Bhasin Sh. Sexual dysfunction in men. Endocrinology. Practice: under. ed. N.M. Avalanche. M., 1999. P.369392. (In Russ.)

12. Tyuzikov I.A., Kalinchenko S.Yu., Vorslov L.O., Tishova Yu.A. The role of estrogen in the male body. Andrology and Genital Surgery. 2014;(4):8-12. (In Russ.)

13. Schill, VB, Komhair F., Hargreave T. Clinical andrology. M.: GEOTAR-Media. 2011. 800 p. (In Russ.)

14. Chacur, M.G.M., Mizusaki K.T., L.R.A. Filho Gabriel, Oba E., Ramos A.A Seasonal effects on semen and testosterone in Zebu and Taurine bulls. Acta Scientiae Veterinariae. 2013;(41):1110.

15. Fejes I., Koloszar S., Zavaczkiz Z.. et al. Effect of body weight on testosterone, estradiol ratio in oligozoospermie patients. Andrologi archive. 2006. P.52, 97-102.

16. Gates M.A. R.A.Mekary, G.R. Chiu et al. Sex steroid hormone levels and body composition in men. J Clin Endocrinol Metab. 2013;98(6):2442-2450.

17. Javed M.T., Abrar K., Mumtaz A. Influence of season on seminal plasma testosterone and oestrogen in healthy and abnormal bulls and their relationship with other semen parameters. Veterinary Archive. 2000;70(3):141-149.

18. Jockenhovel F. Male hypogonadism. Auflage-Bremen: UNIMED. 2004. 188 p.

19. Kozumplik J. The level of plasma testosterone during the prenatal and postnatal period of development in bulls. Acta Vet Brno. 1981;(50):27-32.

20. Kumanov P., Nandipati K., Tomova A., Agarwal A. Inhibin B is a better marker of spermatogenesis than other hormones in the evaluation of male factor infertility. Fertil. Steril. 2006;86(2):32-338

21. Schneider G., Kirschner M.A., Berkowitz R. and Ertel N.H. Increased estrogen production in obese men. The Journal of Clinical Endocrinology \& Metabolism. 1979;48(4):633-638.

22. Wagner R.K. Acta endocrinology. 1978. P.73.

23. Zumoff B., G.W. Strain, J. Kream et al. Obese young men have elevated plasma estrogen levels but obese premenopausal women do not. Metabolism. 1981;30(10):1011-1014.

\section{ABOUT THE AUTHORS:}

Akhmedaga I. Abilov, Doctor of Biol. Sci., Professor, Chief Researcher

Fannur R. Zaripov, General Director

Mikhail I. Dunin, Candidate of Biological Sciences

Elena A. Pyzhova, Candidate of Biological Sciences, Associate Professor 